\title{
O pesadelo mortal de John Carpenter projetado nas idéias de Walter Benjamin
}

\section{Rogério Ferraraz \& Maria Ignês Carlos Magno}

\section{Resumo:}

Nossa proposta visa retomar os estudos de Walter Benjamin para verificar se ainda são atuais e recorrentes algumas de suas temáticas nas mais diferentes áreas da produção cultural massiva e midiática. Neste artigo, escolhemos três temas tratados por Benjamin, o da aura, o da coleção e o da experiência, para discutirmos um exemplo da produção audiovisual contemporânea, o telefilme de horror Pesadelo mortal, do cineasta John Carpenter, feito para a série Mestres do Terror, em 2005. Consideramos pertinente essa discussão não só porque favorece um debate maior sobre os gostos e os repertórios estéticos na cultura midiática, vista como um espaço de mediação entre o massivo e o popular, mas porque possibilita também, através do estudo de um caso exemplar do audiovisual contemporâneo - um filme de gênero dirigido por um cineasta autoral para uma série de televisão -, a revisão e a atualização dos estudos culturais e da teoria da cultura de massa, através de um de seus principais pensadores.

\section{Palavras Chave:}

Audiovisual contemporâneo, John Carpenter, Walter Benjamin, aura, coleção, experiência.

\begin{abstract}
:
Our proposal aims to resume the studies of Walter Benjamin to verify that applicants are still present and some of their themes in different areas of cultural production and mass media. In this paper we choose three themes studied by Benjamin, the aura, the collection and the experience, to discuss an example of contemporary audiovisual production, the horror film Cigarette Burns, by the filmmaker John Carpenter, made for the series Masters of Terror, in 2005. We consider this relevant discussion not only because it favors a larger debate about the aesthetic tastes and repertoires in media culture, seen as a mediator between the massive and popular, but also because it enables the revision and updating of cultural studies and theory of mass culture, through one of its leading thinkers, by studying a relevant example of contemporary audiovisual - a genre film directed by an author filmmaker for a television series.
\end{abstract}

\section{Keywords:}

Contemporary audiovisual, John Carpenter, Walter Benjamin, aura, collection, experience.

É quase impossível falar em modernidade e cinema sem pensar em Walter Benjamin. Não porque o autor se tornou referência obrigatória nas academias desde os Estudos Culturais, como aponta e critica Beatriz Sarlo (2000) em um de seus ensaios sobre o filósofo, mas porque Benjamin acompanhou e aprofundou os estudos sobre as transformações sociais, culturais e tecnológicas ocorridas naquele momento da história e, principalmente, porque, conforme observa Robert Stam, ele pensou o cinema como um meio que "enriquecia o campo da percepção humana e ampliava a consciência crítica da realidade" (STAM, 2003: 84) e também porque "o cinema exemplificava e configurava, ele próprio, uma espécie de mutação da percepção ajustada a uma nova era da evolução social e tecnológica" (STAM, 2003: 85). O filme, dizia Benjamin no texto "A obra de arte na era de sua reprodutibilidade técnica", escrito originalmente entre os anos 1935 e 1936, "serve para exercitar o homem nas novas percepções e reações exigidas por um 
aparelho técnico cujo papel cresce cada vez mais em nossa vida cotidiana” (BENJAMIN, 1996: 174).

O cinema significou tanto para Benjamin que, em Passagens (2006), escrito entre 1927 e 1940, a forma de trabalho adotada pelo filósofo foi a da técnica da montagem cinematográfica: fragmentária e fragmentada. Com uma argumentação não linear, mas, segundo descreve Leo Charney, "por meio de idéias, [em que] citações descontínuas eram apresentadas sem transições e comentários de intervenção que geralmente caracterizam o argumento dos ensaios" (CHARNEY, 2001: 391), Benjamin, além de associar a colagem conceitual à montagem cinematográfica, afirmou explicitamente que tal projeto estava intimamente ligado à montagem, acrescentando em seguida que o método do projeto seria o da montagem literária (CHARNEY, 2001: 391-392). Mais importante ainda, tal projeto buscava "transportar o princípio da montagem para a história" (BENJAMIN apud CHARNEY, 2001: 392).

Benjamin interessa e é referência porque demonstrou que a filosofia é parte da totalidade da cultura e não algo fora ou acima dela, e também, porque pensou o cinema filosoficamente. Em muitos momentos, pensou a história e a filosofia a partir do cinema, porque, para ele, de acordo com Robert Stam, o "impacto epistemológico do novo meio era progressista" (STAM, 2003: 84) e "as formas midiáticas de massa como a fotografia e o cinema construíam novos paradigmas artísticos que refletiam as novas forças históricas; não poderiam, portanto, ser julgadas pelos antigos padrões" (STAM, 2003: 84), como faziam os críticos conservadores da época, e porque também, segundo Julio Cabrera, as imagens cinematográficas colocam questões filosóficas "tão contundentes, ou mais ainda, do que as veiculadas pela escrita" (CABRERA, 2006: 17).

Nossa proposta não é a de retomar os estudos de Benjamin como ilustração de uma idéia ou de uma obra, mas a de perceber como ele captou, viveu e analisou o instante das transformações radicais da história e da cultura, e o quanto ainda são atuais e recorrentes algumas de suas temáticas nas mais diferentes áreas da produção cultural, sejam as ditas artes eruditas ou os processos e produtos da comunicação massiva e midiática. Para esse exercício, escolhemos três temas tratados por Benjamin, e exaustivamente trabalhados e explicados pelos teóricos e estudiosos da comunicação - o da aura, o da coleção e o da experiência -, para discutirmos um exemplo da produção audiovisual contemporânea, o filme de médiametragem de horror Pesadelo mortal (Cigarette Burns, 59 min., Estados Unidos, 2005), feito para a série de televisão Mestres do Terror (Masters of Horror) e dirigido pelo cineasta norte-americano John Carpenter (1).

É claro que os estudos de Benjamin tinham como foco central a destruição da aura que envolvia as obras de arte enquanto objetos raros e únicos. Para ele, como lembra Grünnewald, "com o progresso das técnicas de reprodução, sobretudo do cinema, a aura, dissolvendo-se nas várias reproduções do original, destituiria a obra de seu estado de raridade" (GRÜNNEWALD, 1983: 11), e quando isso ocorria, quando a obra de arte saía da atmosfera religiosa que a envolvia, a dissolução da aura atingia grandes dimensões sociais. Não é esse exatamente o caso do telefilme em questão, mesmo porque a discussão de Benjamin era de outra natureza. Sua preocupação era a de discutir a perda da aura e as consequiências sociais que resultavam desse fato, "particularmente sensíveis no cinema, no qual a reprodução de uma obra de arte carrega consigo a possibilidade de uma radical mudança qualitativa na relação das massas com a arte" (GRÜNNEWALD, 1983: 11). Mesmo assim, consideramos interessante trazer essa discussão para um telefilme de terror contemporâneo, não só porque favorece um debate maior sobre os gostos e os repertórios estéticos na cultura midiática, vista como um espaço de mediação entre o massivo e o popular, mas porque possibilita também, através do estudo de um caso exemplar da produção audiovisual contemporânea, um filme de gênero (o horror, no caso), feito para uma série de televisão de um canal a cabo (Showtime Network) e dirigido por um cineasta autoral, mas que atua dentro do sistema de produção norte-americano, a revisão e a atualização dos estudos culturais e da teoria da cultura de massa, através da 
obra um de seus principais pensadores.

\section{"Filme é magia. E nas mãos certas, uma arma"}

É justamente essa afirmação que abre Pesadelo mortal, dita em voz off, sobre a imagem de um projetor cinematográfico sendo ligado. Não se sabe, nesse momento, de quem é essa voz. Logo em seguida, vemos um jovem chegando de carro a uma mansão. Trata-se de Kirby Sweetman (Norman Reedus), uma espécie de detetive ou caçador de raridades, que é contratado pelo milionário colecionador Sr. Bellinger (Udo Kier) para encontrar um filme único, dado como destruído: La Fin Absolue Du Monde ( $O$ fim absoluto do mundo), do diretor Hans Backovic, realizado em 1971.

É interessante notar que, logo nesse início, duas marcas estílisticas do telefilme ficam explícitas: o jogo de referências e citações, e o uso criativo dos clichês de gêneros, no caso aqui o horror. Assim que Kirby é recebido por um mordomo oriental, ele é levado a uma sala, para se encontrar com o Sr. Bellinger. No corredor, um cartaz do clássico de horror expressionista Nosferatu (1921), do alemão F. W. Murnau. Vivendo o Sr. Bellinger, um ator reconhecido e renomado no gênero horror, o também alemão Udo Kier. A própria imagem do projetor na abertura e o argumento básico do telefilme (um colecionador atrás de um filme raro), pressupondo a possibilidade, que se concretizará, da estrutura de filme-dentro-do-filme, indicam um terreno fértil para esse jogo criativo entre clichê, citação e referência.

O teórico e escritor Umberto Eco, em um texto chamado "A inovação do seriado", ao estabelecer uma "tipologia da repetição" (ECO, 1989: 122), atenta para o fato de que uma das principais características do audiovisual contemporâneo (ele trata basicamente do cinema e da televisão) é o que ele denomina de "dialogismo intertextual" (ECO, 1989: 125) (2). Eco observa que: "Mais interessante é quando a citação é explícita e consciente: estamos então próximos da paródia ou da homenagem ou, como acontece na literatura e na arte pós-moderna, do jogo irônico sobre a intertextualidade (romance sobre o romance e sobre as técnicas narrativas, poesia sobre a poesia, arte sobre a arte)" (ECO, 1989: 125).

Eco atenta ainda que, para que o espectador possa usufruir desse artifício, ele deve conhecer os "lugares originais" (ECO, 1989: 126): aquilo que se presta ao jogo deve fazer parte de uma "enciclopédia do espectador" (ECO, 1989: 126). Não é de estranhar, assim, que, em Pesadelo mortal, o personagem Kirby, além de detetive particular, seja também proprietário de um cinema decadente, o Vogue, que passa apenas filmes fora do chamado mainstream. O próprio Bellinger, ao ser questionado pelo jovem porque havia o escolhido para a tarefa, responde: "Porque você tem bom gosto como programador". Como veremos mais tarde, o filme que tal cinema exibe naqueles dias é Prelúdio para matar (Profondo Rosso), clássico do cinema de horror italiano, dirigido, em 1975, por Dario Argento, principal criador de giallos (3).

Até chegar àquele ponto do diálogo entre Kirby e Bellinger, muitos detalhes já foram explicitados ao telespectador sobre a história de Pesadelo mortal e do filme-dentro-do-filme $O$ fim absoluto do mundo: na sala de Bellinger, atrás de sua mesa, vemos um par de asas pendurado na parede, como se fosse a recordação "viva" de um ato violento (ao modo das cabeças de animais empalhados por caçadores); Kirby diz saber que $O$ fim absoluto do mundo passou uma vez, na abertura do Festival de Cinema Fantástico de Sitges, na Espanha, mas a violência tomou conta do cinema (saberemos mais tarde que a sessão transformou-se em carnificina, resultando na morte dos presentes); ainda segundo Kirby, o diretor Backovic, que acabou abandonando a carreira, tentou sair do país, mas o governo confiscou o filme e o destruiu, sem saber que era ainda um trabalho inacabado e que era a única cópia; o filme, portanto, só teria sido visto por aquele público. Bellinger esclarece para Kirby que o governo não destruiu o filme e que ele possui um objeto de cena de $O$ fim absoluto do mundo. Segundo o colecionador, aquele filme tem um poder real. Bellinger diz que tinha os ingressos para aquela exibição, mas que preferiu ver a estréia do primeiro filme do Dr. Phibes (4), esperando encontrar Vincent Price (em mais uma peça do quebra-cabeça 
de referências e citações de Pesadelo mortal). Ainda de acordo com Bellinger, o Festival de Roterdã, na Alemanha, anunciara, em 1983, uma exibição do filme, mas acabaram cancelando, provavelmente por causa do incêndio que tomou conta do lugar. Kirby contesta: "O fim absoluto do mundo é mais do que raro. Se existisse uma cópia, eu saberia". Bellinger, então, afirma categoricamente: "Existe. Acredite. Minha fonte é infalível”. O colecionador leva Kirby para outra sala, para que ele conheça uma das estrelas do filme: um ser muito branco, sem sobrancelhas, já um pouco envelhecido, preso por correntes; ele tem dois grandes ferimentos em suas costas, como se duas asas tivessem sido arrancadas. Este anjo caído (5), um "prisioneiro dissecado" a quem Bellinger chama de alma, diz: "Nós éramos parte do filme, ligados ao negativo, como a alma à carne. Se ele houvesse sido destruído, nós saberíamos".

Assim, em Pesadelo mortal, temos um colecionador que procura um filme raro, único e maldito. O filme, mesmo tendo sido feito com as técnicas que propiciavam a sua reprodução e exposição, e embora tivesse sido projetado uma vez, continuava único, original, autêntico, conservando ou, melhor dizendo, criando em torno de si uma aura, "uma figura singular, composta de elementos espaciais e temporais: aparição única de uma coisa distante, por mais perto que esteja" (BENJAMIN, 1996: 170) (6). Por ser inacessível e porque estava longe e inatingível, $O$ fim absoluto do mundo conservava a sua autenticidade tornando-se, além de objeto do desejo, um objeto de culto, mesmo secularizado e produzido pelo meio técnico que significava a dissolução da aura pela possibilidade das inúmeras reproduções do original: o cinema. $\mathrm{O}$ fato de o colecionador não ter assistido ao filme, e nem o possuir porque era dado como desaparecido, reforça essa visão.

O que movia o colecionador a buscar o filme raro era o seu poder: "O filme tem um poder real e é esse poder real do filme que me move". Portanto, mesmo feito para ser reproduzido e difundido, o filme se mantinha aurático e sagrado. Quase contrariando o que Benjamin dizia sobre a reprodutibilidade técnica como decisiva na emancipação da arte frente ao seu caráter religioso e ritualístico, na medida em que abria caminho para uma descoberta decisiva porque, "com a reprodutibilidade técnica, a obra de arte se emancipa, pela primeira vez na história, de sua existência parasitária, destacando-se do ritual" (BENJAMIN, 1996: 171). Assim, o filme-dentro-do-filme $O$ fim absoluto do mundo aproxima-se mais do antigo sentido: mágico e religioso, reafirmando o que explicitava Benjamin porque "o valor único da obra de arte "autêntica" tem sempre um fundamento teológico, por mais remoto que seja: ele pode ser reconhecido, como ritual sacralizado, mesmo nas formas mais profanas do culto do Belo" (BENJAMIN, 1996: 171).

Outro aspecto interessante no filme é a própria figura do colecionador. Quando chama o detetive em sua casa e pede para que ele encontre o filme raro, o Sr. Bellinger fala que não colecionava apenas filmes e mostra a ele outro objeto raro de sua coleção: o anjo do filme e dono das asas expostas na parede. Em Passagens, Benjamin escreveu:

É decisivo na arte de colecionar que o objeto esteja desligado de todas as suas funções primitivas, a fim de travar a relação mais íntima que se pode imaginar com aquilo que lhe é semelhante. Esta relação é diametralmente oposta à utilidade e situa-se sob a categoria singular da completude. $\mathrm{O}$ que é essa completude? É uma tentativa de superar o caráter totalmente irracional de sua mera existência através da integração em um sistema histórico novo, criado especialmente para esse fim: a coleção (BENJAMIN, 2006: 239).

Em outra seqüência, já próxima ao final de Pesadelo mortal, quando o detetive Kirby entrega as latas com o filme raro para o colecionador Bellinger e este passa as mãos sobre o objeto, fecha os olhos e estremece, podemos visualizar e entender as palavras de Benjamin sobre a figura do colecionador, quando ele dizia que: "O mais profundo encantamento do colecionador consiste em inscrever a coisa particular em um círculo mágico no qual ela se imobiliza, enquanto percorre um último estremecimento (o estremecimento 
de ser adquirida)" (BENJAMIN, 2006: 239).

É preciso ressaltar que o Sr. Bellinger não é o único colecionador retratado em Pesadelo mortal. Timpson (Christopher Gauthier), funcionário do Vogue e amigo de Kirby, tem a mania de recortar e colecionar os fotogramas dos filmes exibidos naquele cinema que contêm as "marcas de cigarro" (as Cigarette Burns do título original - numa tradução literal seriam "queimaduras de cigarro"). De acordo com Scott Swan (7), um dos roteiristas de Pesadelo mortal, as "marcas de cigarro" eram pequenas marcas feitas no canto direito superior do fotograma que indicavam que haveria mudança de rolo do filme que estava sendo projetado. Isso reforçaria a idéia, segundo Swan, de que Pesadelo mortal, na verdade, é uma espécie de homenagem aos filmes experimentais e transgressores dos anos 1960 e 1970. É interessante observar que, no telefilme, Timpson explica a Kirby: "Quando você assiste a um filme e ela aparece, é para avisar: algo vai acontecer. Você as tira e, de repente, é anarquia".

Assim, devemos retomar mais algumas das reflexões feitas por Benjamin a respeito do colecionador e sua relação com os objetos e como essas reflexões aparecem no filme. Benjamin, para explicar como os objetos chegam até o colecionador, retoma a idéia desenvolvida por Bergson sobre a percepção como uma função do tempo: "Poder-se-ia dizer que, se vivêssemos segundo um outro ritmo - mais serenos diante de certas coisas, mais rápidos diante de outras -, não existiria para nós nada "duradouro", mas tudo se desenrolaria diante de nossos olhos, tudo viria de encontro a nós. Ora, é exatamente isso que se passa com o grande colecionador em relação às coisas. Elas vão até ele. Como ele as persegue" (BENJAMIN, 2006: 240).

Pois, segundo o autor, é preciso saber que:

Para o colecionador, o mundo está presente em cada um de seus objetos e, ademais, de modo organizado. Organizado, porém, segundo um arranjo surpreendente para uma mente profana. [...] Basta que nos lembremos quão importante é para cada colecionador não só o seu objeto, mas também todo o passado deste, tanto aquele que faz parte de sua gênese e qualificação objetiva, quanto os detalhes de sua história aparentemente exterior: proprietários anteriores, preço de aquisição, valor etc. tudo isso, os dados "objetivos", assim como os outros, forma para o autêntico colecionador em relação a cada uma de suas possessões uma completa enciclopédia mágica, uma ordem do mundo, cujo esboço é o destino de seu objeto (BENJAMIN, 2006: 241).

Neste sentido, vemos a importância dos pormenores ocultos dos objetos que nos são familiares, e que a câmera é capaz de revelar. Aparentemente insignificantes e ingênuas, as mercadorias repousam nas vitrines das galerias à espera de ávidos consumidores, ou de colecionadores, sejam de livros, grampos, pedaços de porcelanas, ou qualquer produto que satisfaça o desejo de possuir e consumir um objeto. No telefilme de Carpenter, as "marcas de cigarro" e o filme raro e maldito.

\section{“Já está dentro de você"}

Em Pesadelo mortal, a partir do esclarecedor encontro com o Sr. Bellinger, Kirby aceita o caso, cobrando o valor de 200 mil dólares, exatamente a quantia que deve a Walter (Gary Hetherington), pai de sua exnamorada Annie (Zara Taylor), que emprestou o dinheiro para que Kirby investisse em seu cinema. Saberemos, a partir de lembranças e de visões fantasmagóricas de Kirby, depois que ele for contaminado pelo filme, que o casal era viciado em heroína e que Annie se matou cortando seus pulsos, nua, dentro de uma banheira. Fica claro que, mais do que a devolução do dinheiro, Walter anseia por vingança.

A primeira pessoa que Kirby procura é o crítico de cinema A. K. Meyers (Chris Britton), que havia escrito sobre $O$ fim absoluto do mundo na ocasião de sua exibição no Festival de Sitges. Meyers diz que 
desistiu de ser crítico após escrever sobre esse filme - e Kirby observa que, desde então, Meyers tenta concluir aquela sua crítica, de forma obsessiva, como comprovam as pilhas de papel espalhadas pela casa. Ficamos sabendo também, através de Meyers, que a frase de abertura de Pesadelo mortal, "Filme é magia. E, nas mãos certas, uma arma", fora pronunciada pelo diretor Backovic. Meyers avisa Kirby: "Confiamos que os cineastas não passarão do limite, mas Backovic quebrou essa confiança: ele queria destruir a audiência", e conclui comparando com Stravinski, cuja Sagração da Primavera teria causado tumulto, mas por acidente; ao contrário da reação violenta do público, esperada e planejada por Backovic com seu filme. Meyers, então, entrega a Kirby as gravações em áudio da entrevista que ele fizera com o diretor.

Nessa entrevista, ao ser perguntado por Meyers sobre a razão de ter feito um filme experimental e evitado a narrativa convencional, Backovic afirma: "A narrativa está morta. Hollywood é uma porcaria, o cinema não é entretenimento". Após ouvir tal gravação, Kirby começa a ter visões, em que, dentro de um círculo de fogo (como se fossem as "marcas de cigarro"), aparece sua antiga namorada, banhada em sangue e gritando. Descobrimos ainda, pela pesquisa feita por Kirby, que praticamente toda a equipe do filme morreu e o diretor de fotografia ficou cego. Kirby procura por um amigo também detetive, Henri (Julius Chapple), que pode ter alguma informação sobre o filme. Henri conta que participou, anos atrás, de uma sessão do filme para alguns milionários europeus, mas que não conseguiu assistir a todas aquelas imagens poderosas e que acabou tendo sua mão deformada no contato com a película. Segundo Henri, o filme "trata-se de uma bala disparada bem no meio do inconsciente coletivo da audiência, cuja única resposta racional é a violência". Ao saber das visões de Kirby, sentencia: "Já está dentro de você".

Com Henri, Kirby consegue o endereço de um homem que pode ter informações sobre $O$ fim absoluto do mundo, mas o amigo o adverte que isso pode ser perigoso. Kirb segue, então, ao encontro de Dalibor (Douglas H. Arthurs). Trata-se de outro colecionador misterioso, que mantém contato com a viúva de Backovic, Katja (Gwynyth Walsh) e possui algumas fotos da produção de $O$ fim absoluto do mundo. Além disso, Dalibor e seus capangas fazem snuff movies (8). Eles dopam Kirby e, quando ele acorda, percebe que a taxista que havia o levado até lá está amarrada a uma cadeira bem a sua frente. Dalibor a decapita enquanto seus capangas filmam toda a ação, para desespero de Kirby. Dalibor, então, comenta: "Eu detesto a falsidade de Hollywood. A lâmina de uma mesa de corte pode ser usada para contar uma mentira". Depois de uma pausa, completa: "Uma tomada. Uma cena ininterrupta. O único corte foi para ela. Alguma coisa acontece quando você aponta a câmera para algo horrível. Aquilo ganha poder". E finaliza, questionando sobre o que poderia ser mais terrível do que um ser divino, com o sangue dourado, sendo machucado e ferido em frente às câmeras. Quando Dalibor ameaça matar Kirb, há uma espécie de flash, depois um corte na cena e, quando a imagem volta, os capangas estão mortos e Dalibor muito ferido. Kirby mata-o e pega o endereço de Katja.

No encontro com Katja, Kirby pergunta sobre quem teria produzido $O$ fim absoluto do mundo. Ela responde que fez várias vezes a mesma pergunta para Backovic, mas ele sempre respondia a mesma coisa: "Quem produziu esse filme, produz várias coisas: caos, dor, sofrimento, fome". Kirby indaga se ela fala do Diabo, ao que ela afirma: "O mal é o mal. Um nome faz diferença?". Depois de contar que o marido ficou obcecado com o filme, enlouqueceu ("o filme entrou nele"), tentou matá-la e depois se matou, Katja entrega as latas de O fim absoluto do mundo para Kirby, dizendo que ele e sua obstinação a fazem lembrar de Backovic.

Kirby entrega, então, o filme ao Sr. Bellinger e é pago pelo serviço. O Sr. Bellinger prepara-se, então, para sua noite de gala, com a exibição particular de $O$ fim absoluto do mundo. Kirby vai ao seu cinema, mas o Vogue está fechado, com as portas acorrentadas. Nesse momento, ele recebe uma ligação e retorna à mansão de Bellinger. Ao chegar lá, encontra o mordomo com o corpo todo retalhado e segurando uma lâmina. Ele acusa Kirby de ter levado o inferno para aquela casa e, então, fura os próprios olhos. Kirby 
corre para a sala de projeção, à procura de Bellinger. Quando ele entra, os créditos finais do filme já estão na tela. Bellinger está atrás do projetor, segurando uma navalha e com sangue nas mãos. O colecionador diz à Kirby que viu $O$ fim absoluto do mundo e que o recomenda, mas que "não é um filme, é uma préestréia, a próxima atração da alma e, no meu caso, é um belo final". Bellinger completa: "Eu não preciso mais dele. Eu fui... inspirado. Fiz o meu próprio filme". Ele, então, prende seu intestino no carretel do aparelho e projeta suas entranhas na tela. Kirby e Walter, que havia o seguido até lá, acabam brigando, quando há outro flash e um novo corte. Quando a imagem volta, os dois estão feridos, vendo $O$ fim absoluto do mundo. Kirby mata Walter e se suicida. O mordomo acaba libertando o anjo, que recupera o filme e agradece ao cadáver de Kirby.

Essa cena do Sr. Bellinger projetando suas próprias entranhas, como se ele próprio fosse o filme a ser exibido ("a próxima atração da alma"), é emblemática porque, além de permitir várias interpretações, suscita muito questionamentos. Por exemplo: até aquele momento do filme não sabemos exatamente o que continha ou era narrado em $O$ fim absoluto do mundo, a única informação que temos é a de que, provavelmente, um anjo foi preso e ferido durante as filmagens e que as pessoas se matavam ou se mutilavam após assistirem ao filme. $\mathrm{O}$ que de tão traumático ou horrível existia naquelas imagens ou história? O fim do mundo ou da narrativa? Que experiência era aquela vivida pelos espectadores que os levava a morte? Que poder era aquele que o filme possuía e que transformava em possuídos todos que com ele entravam em contato? Sempre a morte após a exibição? Qual morte? Do mundo? Da história? Da arte de narrar? Da experiência do cinema? Não sabemos. O que sabemos é que a experiência de olhar aquelas imagens é extrema. E aqui surgem outras reflexões que talvez se liguem com o ato de projetar as próprias entranhas e viver a sensação única, ou a experiência do momento, do instante e a retomada da aura, interligadas também nas reflexões de Benjamin. Basta lembrarmos que, apesar de as reflexões sobre a experiência terem sido uma constante na produção de Benjamin, discutida sob diferentes aspectos desde os escritos da juventude até os da maturidade, quando retoma os estudos sobre a experiência ou a degradação da experiência no mundo moderno, nos anos de 1930, analisa também, em escritos paralelos, a perda da aura. Escritos paralelos que talvez possam ser pensados naquela seqüência de Pesadelo mortal. Se pensarmos a cena da projeção das entranhas como a vivência de uma sensação plena que marca o momento único, o êxtase do momento plenamente sentido a ponto de não permitir que nenhuma outra sensação coabite aquele instante, como a sensação momentânea ao da experiência da visão, o de estar presente no presente, no "aqui e agora da reconhecibilidade", voltamos à questão da aura e sua relação com a experiência do olhar, porque, nas palavras de Benjamin: "o olhar consegue na sua plenitude a experiência da aura" (BENJAMIN, 1983: 53) e "perceber a aura de uma coisa significa dotá-la da capacidade de olhar" (BENJAMIN, 1983: 53), mesmo que esse olhar tenha sido mediado pela máquina.

\section{E agora, Benjamin?}

Com isso, outras perguntas podem ser feitas a partir da análise de Pesadelo mortal: para o colecionador, projetar suas entranhas significava fazer um filme único? Viver o prazer do momento e o esvaecimento desse mesmo momento com a morte? À maneira do poema de Baudelaire, em que o cidadino vive o êxtase, porém, "o êxtase do cidadino é um amor não já à primeira vista, e sim à última vista. É uma despedida para sempre que, na poesia, coincide com o instante do enlevo" (BENJAMIN, 1983: 38), o prazer da visão e a morte do sujeito. A transfiguração do olhar que olha, e por não suportar o que vê, mutila os próprios olhos e entrega a chave para que o anjo aprisionado liberte-se, como faz o mordomo do Sr. Bellinger, em Pesadelo mortal. Ou liberte o filme que havia sido transformado em sagrado, portanto, aurático? Ao ser libertado, o anjo recupera as latas com $O$ fim absoluto do mundo, passa pelo detetive Kirby, que se matou após ter visto o filme, e o agradece por ele ter lhe "devolvido a alma" - ou libertado o filme de seu valor de culto e devolvido a ele aquilo que é próprio do cinema: a sua reprodutibilidade. Portanto, o fim da aura e a liberdade de poder ser multiplicado. Era esse exatamente o pensamento de Benjamin quanto ao poder do cinema. Para ele, era a reprodutibilidade técnica da obra de arte que 
modificava a relação desta com a massa. Afinal, o filme é magia. E, nas mãos certas, uma arma.

Assim, o objetivo deste artigo, conforme exposto no início do texto, era o de observar, em que medida, é possível resgatar e renovar alguns estudos e conceitos desenvolvidos por Walter Benjamin até os anos 1940, verificando, na análise de uma obra audiovisual contemporânea, o alcance e a atualidade do pensamento benjaminiano. Para tanto, escolhemos o telefilme Pesadelo mortal, dirigido, em 2005, por um reconhecido autor do gênero horror, John Carpenter, para uma série de televisão a cabo. Se não esgotamos (longe disso) as questões levantadas nesse breve exercício, ao menos esperamos que nossa reflexão sirva tanto para estimular novos olhares para certas obras consagradas da teoria crítica, dos estudos culturais e da teoria da cultura de massa, como para ampliar as possibilidades de análise dos produtos da cultura midiática contemporânea, sejam eles de qualquer natureza, gênero ou formato. Afinal, diante de todas as novas configurações expressivas, econômicas, culturais e tecnológicas de nosso tempo, nos perguntamos: e agora, Benjamin?

\section{Bibliografia:}

BENJAMIN, Walter. "A obra de arte na era de sua reprodutibilidade técnica". In: Magia e técnica, arte e política: ensaios sobre literatura e história da cultura. $7^{\mathrm{a}}$. ed. $10^{\mathrm{a}}$. reimp. São Paulo: Brasiliense, 1996, pp.165-196.

\section{(coleção Os Pensadores).}

. "Sobre alguns temas em Baudelaire". In: Textos escolhidos. São Paulo: Abril Cultural, 1983

. Passagens. Organizada por Willi Bolle. Belo Horizonte: Editora UFMG; São Paulo: Imprensa Oficial do Estado de São Paulo, 2006.

CABRERA, Julio. O cinema pensa. Uma introdução à filosofia através dos filmes. Rio de Janeiro: Rocco, 2006.

CHARNEY, Leo. "Num instante: o cinema e a filosofia da modernidade". In: O cinema e a invenção da vida moderna. Organizada por Leo Charney e Vanessa R. Schwartz. São Paulo: Cosac Naify, 2001, pp.386-408.

CHAUI, Marilena. Simulacro e poder. Uma análise da mídia. São Paulo: Fundação Perseu Abramo, 2006.

ECO, Umberto. “A inovação do seriado". In: Sobre os espelhos e outros ensaios. Rio de Janeiro: Nova Fronteira, 1989.

GRÜNNWALD, José Lino. "Benjamin: cinema e revolução". In: BENJAMIN, Walter. Textos escolhidos. São Paulo: Abril Cultural, 1983 (coleção Os Pensadores).

MACHADO, Arlindo. A televisão levada a sério. 4a . ed. São Paulo: Senac, 2005.

PALLOTTINI, Renata. Dramaturgia de televisão. São Paulo: Moderna, 1998.

SARLO, Beatriz. Siete ensayos sobre Walter Benjamín. Argentina: Fondo de Cultura Econômica de 
Argentina, 2000.

STAM, Robert. Introdução à teoria do cinema. Campinas, São Paulo: Papirus, 2003.

\section{Fontes}

IMDb. The Internet Movie Database. Disponível em: http://www.imdb.com.

KONIGSBERG, Ira. The Complete Film Dictionary. 2a . ed. New Cork: s/e: 1997.

\section{Ficha Técnica}

Pesadelo mortal (John Carpenter’s Cigarette Burns, Canadá/EUA, 2005, 59min.).

Episódio integrante da série Mestres do Terror (Masters of Horror), do canal Showtime, criada por Mick Garris.

Produção: IDT Entertainment / Nice Guy Productions / Industry Entertainment.

Direção: John Carpenter.

Roteiro: Drew McWenny / Scott Swan.

Música: Cody Carpenter.

Elenco: Norman Reedus (Kirby Sweetman), Udo Kier (Sr. Bellinger), Gary Hetherington (Walter), Zara Taylor (Annie), Christopher Gauthier (Timpson), Chris Britton (A. K. Meyers), Julius Chapple (Henri), Douglas H. Arthurs (Dalibor), Gwynyth Walsh (Katja).

\section{Notas:}

Uma primeira versão deste artigo foi apresentada no Grupo de Trabalho Cultura das Mídias no XIX Encontro da Compós, PUC-RJ, em junho de 2010.

(1) Entre outros diretores renomados que dirigiram telefilmes para essa série estão Dario Argento, Joe Dante, John Landis, Tobe Hooper, Takashi Miike, entre outros. Os telefilmes de Mestres do Terror seriam o que Arlindo Machado (2005) e Renata Pallottini (1998) chamam de episódios unitários, pertencentes a um formato de programa seriado em que apenas o espírito ou a temática geral das histórias se repetem. Machado diz: "em cada unidade, não apenas a história é completa e diferente das outras, como diferentes também são os personagens, os atores, os cenários e, às vezes, até os roteiristas e diretores" (MACHADO, 2005: 84).

(2) Vários autores, nacionais e estrangeiros, apontaram o uso abundante da metalinguagem e do jogo paródico como marcas características da arte e da cultura pós-moderna, que, nos parece, mantém seu 
alcance na produção audiovisual contemporânea. Entre esses autores, podemos citar Renato Luiz Pucci Jr., Andreas Huyssen, Linda Hutcheon, entre outros.

(3) Giallo é um subgênero do horror; desenvolvido principalmente na Itália nos anos 1970, é um tipo de filme violento, carregado de suspense, em que psicopatas e matadores em série assassinam geralmente jovens, em narrativas de mistério. O termo giallo significa amarelo em italiano, evocando a cor da capa de livros muito baratos e populares, com histórias de horror e de crimes, vendidos em bancas de jornal na Itália.

(4) O abominável Dr. Phibes (The Abominable Dr. Phibes, Inglaterra, 1971, 91 min.), dirigido por Robert Fuest.

(5) Ou "ser gracioso", como denominado no roteiro original, conforme conta Drew McWeeny, um dos roteiristas principais do telefilme, nos extras do DVD de Pesadelo mortal, lançado no Brasil pela Paris Filmes.

(6) Conceito desenvolvido por Benjamin em "A obra de arte na era de sua reprodutibilidade técnica", ensaio que, conforme Marilena Chauí, acompanha o "movimento histórico e social da passagem das artes do campo religioso ao de sua autonomia ou o campo artístico propriamente dito" (CHAUÍ, 2006, p.23) e distingue o momento religioso do momento autônomo pela diferenciação entre seu "valor de culto" e seu "valor de exposição". Para realizar essa análise, Benjamin introduz o conceito de aura, ou "a absoluta singularidade de um ser natural ou artístico" (CHAUÍ, 2006, p.23).

(7) Informação retirada dos extras do DVD de Pesadelo mortal.

(8) Snuff movies seriam filmes documentais de pessoas sendo mortas, de forma violenta, enquanto são filmadas. Circulariam entre colecionadores que pagariam altas cifras por estes filmes amadores.

\section{Mini Currículo :}

Rogério Ferraraz é professor no Programa de Pós-Graduação em Comunicação da Universidade Anhembi Morumbi (São Paulo).

Maria Ignês Carlos Magno é professora no Programa de Pós-Graduação em Comunicação da Universidade Anhembi Morumbi (São Paulo). 